\title{
Evaluación del valor nutricional de recetas típicas elaboradas con maíz común y biofortificado en el Departamento del Cauca, Colombia
}

\author{
Paola Catalina Imbachí-Narváez,, ${ }^{(1,2)}$ Dayron Gutiérrez, Tec Quím y de Alim, ${ }^{(2)}$ \\ Darwin Ortiz, Quím, (2) Helena Pachón, PhD, MPH. ${ }^{(2)}$
}

\author{
Imbachí-Narváez PC, Gutiérrez D, Ortiz D, Pachón H. \\ Evaluación del valor nutricional de recetas típicas \\ elaboradas con maíz común y biofortificado \\ en el Departamento del Cauca, Colombia. \\ Salud Publica Mex 2010;52:305-3 I4.
}

\section{Resumen}

Objetivo. Investigar si el maíz QPM (con más triptófano y lisina) presentaba mejor calidad proteica que el maíz común (MC) utilizándolo en preparaciones colombianas. Material y métodos. Entre 2008 y 2009, en el CIAT, Palmira, Colombia, se evaluó la concentración de triptófano, proteína soluble (PS) y digestibilidad in vitro de proteína (DP) en 10 recetas, preparadas con QPM o MC. Resultados. El triptófano osciló entre 0.011 y $0.072 \%$ para MC y 0.012 y $0.107 \%$ para QPM. Las recetas de QPM presentaron mayor o igual concentración de triptófano que las recetas de MC. PS osciló entre 2.359 y $14.783 \mathrm{~g} / \mathrm{kg}$ para MC, y 3.339 y $16.839 \mathrm{~g} / \mathrm{kg}$ para QPM. Las recetas de QPM, exceptuando una, presentaron mayor o igual concentración de PS. DP estuvo entre 75 y $84 \%$ para ambos maíces. Sólo cuatro recetas presentaron diferencia de DP entre QPM y MC. Conclusiones. Las recetas de maíz QPM son de mejor calidad proteica.

Palabras clave: maíz; triptófano; proteína; Colombia

\author{
Imbachí-Narváez PC, Gutiérrez D, Ortiz D, Pachón H. \\ Evaluation of the nutritional value of typical \\ recipes from the Cauca Department in Colombia prepared \\ with common and biofortified maize. \\ Salud Publica Mex 2010;52:305-314.
}

\begin{abstract}
Objective. Ten typical recipes from southwestern Colombia were evaluated at CIAT in Palmira, Colombia between 2008 and 2009. Material and Methods. The recipes were prepared in a traditional manner, using quality protein maize (QPM, with more tryptophan and lysine) or common maize (CM); each of these was either fresh kernel or dry grain, or white or yellow maize, per the recipe. The two types of maize were compared for their protein quality. Results. Tryptophan concentrations were $0.011-0.072 \%$ and 0.012 $0.107 \%$ for CM and QPM, respectively. Tryptophan values for QPM recipes were greater than or equal to those for CM recipes. Soluble protein ranged from $2.359-14.783 \mathrm{~g} / \mathrm{kg}$ for $\mathrm{CM}$ and $3.339-16.839 \mathrm{~g} / \mathrm{kg}$ for QPM. Except for one recipe, soluble protein in QPM recipes was greater or equal to that of CM recipes. In vitro protein digestibility was $75-84 \%$ for recipes prepared with both maize types. Only four recipes had a statistically significant difference between QPM and CM with regard to digestibility. Conclusions. Most recipes prepared with QPM had a higher protein quality than those prepared with CM.
\end{abstract}

Keywords: Maize; tryptophan; protein; Colombia

(I) Facultad de Ciencias Agropecuarias, Universidad del Cauca. Colombia

(2) Centro Internacional de Agricultura Tropical, CIAT. Colombia

Fecha de recibido: 7 de agosto de 2009 - Fecha de aceptado: 17 de mayo de 2010 Solicitud de sobretiros: Helena Pachón. Centro Internacional de Agricultura Tropical, (CIAT).AA 67I3. Cali, Colombia Correo electrónico: h.pachon@cgiar.org 
L os cereales como el maíz son una fuente importante de alimentación en los países en vías de desarrollo. ${ }^{1}$ Según la Encuesta Nacional de la Situación Alimentaria y Nutricional 2005 de Colombia, 6.2\% de los colombianos consumían maíz, 6.2\% harina de maíz y 17.9\% arepa elaborada con harina de maíz, en una cantidad promedio de 87.5, 49.7 y $17.9 \mathrm{~g} /$ individuo/ día, respectivamente. ${ }^{2}$ Para 2003, el maíz aportaba cerca de $12 \%$ de la proteína consumida en Colombia; ${ }^{3}$ sin embargo, ésta es de origen vegetal y tiene menor contenido de aminoácidos esenciales y digestibilidad que la animal. ${ }^{4}$

La biofortificación es una estrategia desarrollada para aumentar el contenido de nutrientes de los cultivos y mejorar sus características agronómicas. ${ }^{5}$ El maíz de alta calidad de proteína (QPM: quality protein maize), es uno de aquéllos y posee doble contenido de los aminoácidos esenciales lisina y triptófano, presentando mejor calidad de proteína (CP). ${ }^{6}$ Como demuestran diferentes autores, ${ }^{7,8,9}$ este maíz puede ser empleado para recuperar el grado normal de nutrición en preescolares con algún grado de desnutrición. No obstante, los procesos de cocción pueden afectar la composición de aminoácidos del maíz, reduciendo la concentración de lisina y triptófano comparado con el grano entero. ${ }^{10} \mathrm{La}$ digestibilidad aparente del maíz opaco-2, precursor del QPM, puede disminuir con el proceso de cocción. ${ }^{10,11}$

En Colombia, se adelantaron estudios agronómicos para evaluar el desempeño de maíces QPM, y se logró el lanzamiento comercial de una variedad blanca y otra amarilla. * Sin embargo, aún no se evalúa el comportamiento nutricional de estos maíces con recetas típicas colombianas. En el presente estudio, se evaluó la concentración de proteína soluble (PS) y del aminoácido triptófano en recetas colombianas elaboradas con maíz QPM o maíz común (MC), además de evaluar la digestabilidad in vitro de proteína (DP) para las mismas. Se realizó este trabajo en el departamento del Cauca porque la prevalencia de baja talla-edad es mayor a la prevalencia nacional (15.0 vs. $10.2 \%),{ }^{2}$ y el departamento es productor y consumidor de maíz. ${ }^{12}$ Por lo anterior, la población del departamento se podría beneficiar con los resultados de esta investigación.

\section{Material y métodos}

Se trabajó con maíz QPM y MC. Grano blanco y amarillo, tierno (choclo) y seco. El maíz QPM blanco (GENEALOGIA-SO3TLWQAB05 ORIGEN-PM06B-062-5 ID-SA1614-18), QPM amarillo (GENEALOGIASO3TLYQAB05 ORIGEN-PM06B-062-5 ID-SA1614-18)

\footnotetext{
* Edgar Burbano, CIAT, comunicación personal.
}

y el maíz tierno amarillo (MTA) común (ICAV-109) los donó el Centro Internacional de Mejoramiento de Maíz y Trigo, CIMMYT, Palmira, Colombia. El maíz seco blanco (MSB) común (Fenalce 365) lo donó el Instituto Colombiano Agropecuario, ICA, Cali, Colombia. El maíz tierno blanco (MTB) común y el maíz seco amarillo (MSA) común, se adquirieron comercialmente en Cali y Timbío, Colombia, respectivamente. Los reactivos y enzimas se adquirieron comercialmente en una multinacional química farmacéutica reconocida. Se empleó agua con conductividad de $18 \mathrm{M} \Omega$.

Recetas: Se recolectó información sobre la elaboración de productos de maíz en el departamento del Cauca, mediante una encuesta aprobada verbalmente por el presidente del Comité de Ética de la Universidad del Cauca. Se encuestaron nueve amas de casa y siete fabricantes de productos de maíz, residentes en Popayán y Timbío. De las 15 recetas obtenidas se seleccionaron 10, teniendo en cuenta al maíz como principal ingrediente, fácil preparación y bajo o ningún aporte proteico de los ingredientes adicionales. Éstas se elaboraron de forma tradicional en el CIAT, Palmira, Colombia (cuadro I).

Cada receta fue congelada, liofilizada, molida (molino de bolas de circonio elaborado artesanalmente) y sometida a extracción de grasa en un equipo Soxhlet, con hexano, a reflujo, hasta retirar completamente la grasa.

Cuantificación de triptófano: Se realizó por el método colorimétrico de Villegas y colaboradores, ${ }^{13}$ modificado por Nurit y colaboradores. ${ }^{14}$ Aunque el maíz QPM se biofortifica en lisina y triptófano, sólo se cuantificó el triptófano, pues se ha encontrado alta correlación entre el contenido de triptófano y lisina en el grano de maíz. ${ }^{15}$

Cuantificación de proteína soluble (PS): Se empleó el método de Lowry y colaboradores. ${ }^{16}$ con algunas modificaciones. A $0.1 \mathrm{~g}$ de muestra liofilizada, se adicionó $20 \mathrm{~mL}$ de $\mathrm{NaOH} 1 \mathrm{M}$, posteriormente se homogenizó y filtró en papel. La solución filtrada se trató según el método y se realizó lectura a una absorbancia a $750 \mathrm{~nm}$.

Digestibilidad in vitro de proteína (DP): Se empleó el método multienzimático de Hsu y colaboradores. ${ }^{17}$ modificado por McDonough y colaboradores. ${ }^{18} \mathrm{El}$ porcentaje de DP se calculó empleando la fórmula: $\% \mathrm{DP}=210.46-18.10 \mathrm{X}$, donde $\mathrm{X}=\mathrm{pH} 10$ min después de iniciada la reacción multienzimática.

Análisis estadístico: Se empleó el software Stata, versión 9. Se compararon los datos de maíz QPM con MC. 


\title{
Cuadro I
}

\section{INGREDIENTES Y PROCESO DE ELABORACIÓN DE LAS RECETAS SELECCIONADAS. Centro Internacional de Agricultura Tropical, 2008-2009}

Receta e ingredientes

Mazamorra de maíz amarillo

$100 \mathrm{~g}$ de maíz seco amarillo entero

$5 \mathrm{~g}$ de bicarbonato de sodio

$800 \mathrm{~g}$ de agua potable
Proceso de elaboración Separar el pericarpio y germen del maíz empleando un molino tradicional. Lavar el maíz. Mezclar y cocinar los ingredientes durante $45 \mathrm{~min}$.

Mazamorra de maíz blanco

$100 \mathrm{~g}$ de maíz seco blanco trillado

$5 \mathrm{~g}$ de bicarbonato

Lavar el maíz. Mezclar y cocinar los ingredientes durante $45 \mathrm{~min}$.

$800 \mathrm{~g}$ de agua potable

\begin{abstract}
Envuelto pelado
$500 \mathrm{~g}$ de maíz amarillo seco entero

$100 \mathrm{~g}$ de ceniza de leña

$20 \mathrm{~g}$ de sal

Agua potable

Hojas de plátano soasadas

Cocinar el maíz con la ceniza durante I h. Lavar el maíz y frotarlo para separar el germen y pericarpio Remojar el maíz durante $5 \mathrm{~d}$. Lavar el maíz cada 20 min durante un día. Moler el maíz finamente.Volver a moler el maíz, agregando $200 \mathrm{~mL}$ agua para mayor facilidad, esta vez con tamaño de partícula más fino. Agregar la sal a la mezcla y cocinar durante $15 \mathrm{~min}$. Colocar una cucharada de la mezcla en un trozo de hoja de plátano. Envolver y amarrar. Cocinar al vapor durante $20 \mathrm{~min}$.
\end{abstract}

Cauncharina

$50 \mathrm{~g}$ de maíz amarillo seco entero

$15 \mathrm{~g}$ de azúcar

Tostar el maíz. Molerlo finamente.Adicionar el azúcar en una proporción 70/30 de maíz/azúcar.

Envuelto añejo

$500 \mathrm{~g}$ de maíz seco blanco trillado

Agua potable

Hojas de plátano soasadas

Arepa

$300 \mathrm{~g}$ de maíz seco blanco trillado

$700 \mathrm{~g}$ de agua potable

$30 \mathrm{~g}$ de sal

$75 \mathrm{~g}$ de margarina

Choclo frito

3 mazorcas de maíz tierno

$50 \mathrm{~mL}$ de aceite vegetal

$5 \mathrm{~g}$ de sal

Choclo cocido

3 mazorcas de maíz tierno

$2 \mathrm{~L}$ de agua potable

$10 \mathrm{~g}$ de sal

Envuelto de choclo

5 mazorcas de maíz tierno

$10 \mathrm{~g}$ de sal

$30 \mathrm{~g}$ de azúcar

Hojas de choclo

Arepa choclo

5 mazorcas de maíz tierno

$10 \mathrm{~g}$ de sal

$30 \mathrm{~g}$ de azúcar

$200 \mathrm{~mL}$ de aceite
Lavar el maíz. Remojar el maíz durante 8 días. Lavar el maíz cada 20 min durante un día, cambiando el agua de remojo. Moler el maíz finamente.Volver a moler el maíz, agregando $200 \mathrm{~mL}$ agua para mayor facilidad, esta vez con tamaño de partícula más fino. Cocinar la mezcla durante $15 \mathrm{~min}$. Colocar una cucharada de la mezcla en un trozo de hoja de plátano. Envolver y amarrar. Cocinar al vapor durante $20 \mathrm{~min}$.

Lavar el maíz.Adicionar el agua y cocinar durante $45 \mathrm{~min}$. Dejar enfriar. Moler finamente.Agregar la sal y la margarina.Armar las arepas. Asarlas en un sartén de teflón durante 5 min.
Desgranar las mazorcas. Lavar el maíz.Adicionar la sal y freír durante $6 \mathrm{~min}$.

Lavar las mazorcas. Colocarlas en el agua, adicionar la sal y cocinar durante 20 min. Escurrir las mazorcas cocidas.
Desgranar las mazorcas. Lavar el maíz. Moler finamente. Agregar los otros ingredientes. Colocar una cucharada de la mezcla en una hoja de choclo. Envolver la masa. Colocar para cocinar al vapor durante $25 \mathrm{~min}$.

Desgranar las mazorcas. Lavar el maíz. Moler finamente.Agregar los otros ingredientes. Poner a calentar el aceite.Agregar una cucharada de masa en el aceite caliente. Freír durante 6 min para dorar. Retirar del aceite y escurrir. 
Los datos de triptófano, PS y DP no presentaron una distribución paramétrica, por lo tanto se aplicó un análisis no paramétrico (Wilcoxon rank-sum test). Un valor $p \leq 0.05$ se consideró estadísticamente significativo.

\section{Resultados}

Triptófano: Para maíz seco, el triptófano fue mayor $(p \leq 0.05)$ en los maíces QPM enteros (cuadro II). En los pasos intermedios de elaboración, se encontró mayor $(p \leq 0.05)$ triptófano en el QPM, exceptuando la arepa de MSB donde no hubo diferencia $(p \leq 0.05)$. Las recetas QPM presentaron mayor $(p \leq 0.05)$ concentración de triptófano, excepto la mazamorra de MSB y la arepa, las cuales no presentaron diferencia $(p \leq 0.05)$ entre QPM y MC.

En el maíz tierno, el MTA QPM entero presentó mayor $(p \leq 0.05)$ concentración de triptófano. En el MTB entero no hubo diferencia ( $p \leq 0.05)$. En los pasos intermedios, el triptófano fue mayor en los QPM $(p \leq 0.05)$. Las recetas elaboradas con maíz tierno QPM presentaron mayor $(p \leq 0.05)$ triptófano, exceptuando la arepa de choclo de MTA, la cual no presentó diferencia $(p \leq 0.05)$.

La concentración del aminoácido expresada en mg triptófano/g nitrógeno (cuadro III) fue mayor en QPM que en $\mathrm{MC}$, tanto en granos como en pasos intermedios y preparaciones finales.

Proteína soluble: Se encontró una correlación positiva $(\mathrm{r}=0.66, p \leq 0.001)$ entre la PS y el porcentaje de nitrógeno $(\% \mathrm{~N})$ de las muestras.

En maíz seco, el MSA entero QPM presentó mayor $(p \leq 0.05)$ concentración de PS (cuadro II). Mientras el MSB entero no presentó diferencia $(p \leq 0.05)$. En los pasos intermedios hubo mayor $(p \leq 0.05)$ PS en los QPM, a excepción de cuatro pasos los cuales no presentaron diferencia. Las recetas, mazamorra de MSA común y envuelto pelado, y mazamorra de MSB QPM presentaron mayor $(p \leq 0.05)$ PS; para las demás no se encontró diferencia $(p \leq 0.05)$.

En maíz tierno, el MTA entero QPM presentó mayor $(p \leq 0.05)$ PS, mientras que el MTB entero no presentó diferencia $(p \leq 0.05)$. En los pasos intermedios, los QPM presentaron mayor PS $(p \leq 0.05)$. Las recetas de MTA QPM y la arepa choclo de MTB presentaron mayor PS $(p \leq 0.05)$. En las otras recetas de MTB no hubo diferencia $(p \leq 0.05)$.

Digestibilidad in vitro de proteina: En las recetas mazamorra de MSA común y mazamorra de MSB QPM se encontró mayor DP $(p \leq 0.05)$ (cuadro IV). Las demás recetas de maíz seco no presentaron diferencia $(p \leq 0.05)$.
En las recetas de maíz tierno, se encontró mayor $(p \leq 0.05)$ DP en el choclo cocido (79\%) y el envuelto de choclo (79\%) de MTB QPM; en las otras de MTB y las de MTA no se encontró diferencia $(p \leq 0.05)$.

\section{Discusión}

Triptófano, maíz seco: $\mathrm{Al}$ igual que reportaron otros autores, ${ }^{10,11,19-22}$ los maíces QPM presentaron mayor concentración de triptófano que los MC. Los valores indican gran variabilidad al ser comparados con otros estudios. ${ }^{11,19,23-25}$

Los pasos intermedios conservaron la diferencia a favor del QPM observada en el maíz entero, exceptuando los de la arepa, donde no hubo diferencia. Al elaborar las recetas tanto en QPM como en MC se observó pérdida del aminoácido, así como reportan otros autores para MC, QPM u opaco-2. ${ }^{10,11,20,26}$ Las pérdidas en los pasos intermedios estuvieron entre 16 y $78 \%$ para QPM y 22-76\% para MC. Aunque en el MC, el maíz trillado de MSB presentó valor de pérdida negativo, éste se asumió como no pérdida.

Las recetas elaboradas con maíz seco QPM presentaron mayor concentración de triptófano, excepto la mazamorra de MSB y la arepa, las cuales no presentaron diferencia. En otros estudios también se reportó mayor triptófano en recetas elaboradas con QPM u opaco-2; ;0,11,26-28 Chávez $^{10}$ encontró doble contenido de triptófano en la arepa de opaco-2; sin embargo en este estudio, esta receta presentó igual triptófano para ambos maíces.

Las pérdidas del aminoácido en las recetas estuvieron entre 64 y $85 \%$ para QPM y entre 41 y cerca del $100 \%$ para MC. Esta última concentración de triptófano, correspondiente a la mazamorra de MSA, fue muy baja, y no se pudo detectar con el método empleado.

Triptófano, maíz tierno: El MTA entero QPM presentó mayor concentración de triptófano que el MTA común, mientras el MTB entero no mostró diferencia. Las recetas de maíz tierno presentan menores pérdidas que las de maíz seco, exceptuando el choclo frito de MTB común, el cual sí presentó pérdida de $83 \%$; para las demás, hubo pérdidas entre 0 y $42 \%$ para MC y 0 y $29 \%$ para QPM, corroborando los resultados presentados por otros autores frente a la pérdida de triptófano, tras el proceso de cocción. ${ }^{10,11,20,26}$ Las recetas elaboradas con maíz tierno QPM presentaron mayor concentración de triptófano, con excepción de arepa de choclo de MTA, que no presentó diferencia. No fue posible comparar estos resultados con otros similares, pues no se encontró literatura sobre la concentración de triptófano en recetas elaboradas con maíz tierno. 
Cuadro II

CONTENIDO (PROMEDIO \pm DE) DE TRIPTÓFANO Y PROTEÍNA SOLUBLE EN EL GRANO ENTERO, PASOS INTERMEDIOS Y RECETAS elaboradas con maíz común y maíz QPM, (N=3). Centro Internacional de Agricultura Tropical, 2008-2009

Maíz seco amarillo

\begin{tabular}{|c|c|c|c|c|c|c|c|c|c|}
\hline \multicolumn{5}{|c|}{ Triptófano } & \multicolumn{5}{|c|}{ Proteína soluble } \\
\hline Común & $P d^{*}$ & $Q P M^{\ddagger}$ & $P d$ & $p^{\S}$ & Común & $P d$ & $Q P M$ & $P d$ & $p$ \\
\hline$\% \#$ & $\%^{\&}$ & $\%$ & $\%$ & & $g / k g^{*}$ & $\%$ & $g / k g$ & $\%$ & \\
\hline
\end{tabular}

Mazamorra

\begin{tabular}{ccccccccccc} 
Maíz entero & $0.047 \pm 0.004$ & & $0.078 \pm 0.007$ & & $p \leq 0.05$ & $11.289 \pm 0.489$ & & $12.891 \pm 0.303$ & $p \leq 0.05$ \\
\hline Maíz trillado & $0.001 \pm 0.001$ & 64 & $0.045 \pm 0.009$ & 42 & $p \leq 0.05$ & $6.060 \pm 0.670$ & 46 & $5.517 \pm 1.319$ & 57 & $p=0.51$ \\
\hline Mazamorra & ND & $\sim 100$ & $0.012 \pm 0.001$ & 85 & & $10.67 I \pm 1.975$ & 5 & $4.103 \pm 0.835$ & 68 & $p \leq 0.05$
\end{tabular}

Envuelto pelado

\begin{tabular}{|c|c|c|c|c|c|c|c|c|c|c|}
\hline Maíz entero & $0.047 \pm 0.004$ & & $0.078 \pm 0.007$ & & $p \leq 0.05$ & II.288+0.489 & & $|2.89| \pm 0.303$ & & $p \leq 0.05$ \\
\hline Maíz pelado & $0.012 \pm 0.002$ & 74 & $0.017 \pm 0.001$ & 78 & $p \leq 0.05$ & $3.214 \pm 0.043$ & 72 & 4. $155 \pm 0.475$ & 68 & $p \leq 0.05$ \\
\hline Maíz remojado & $0.012 \pm 0.002$ & 74 & $0.028 \pm 0.000$ & 64 & $p \leq 0.05$ & $2.519 \pm 0.033$ & 78 & $4.265 \pm 0.723$ & 67 & $p \leq 0.05$ \\
\hline Masa & $0.012 \pm 0.000$ & 74 & $0.038+0.001$ & 52 & $p \leq 0.05$ & $2.522 \pm 0.516$ & 78 & $4.108+0.934$ & 68 & $p \leq 0.05$ \\
\hline Envuelto pelado & $0.011 \pm 0.001$ & 76 & $0.028 \pm 0.000$ & 64 & $p \leq 0.05$ & $2.359 \pm 0.268$ & 79 & $3.339 \pm 0.122$ & 74 & $p \leq 0.05$ \\
\hline \multicolumn{11}{|l|}{ Cauncharina } \\
\hline Maíz entero & $0.047 \pm 0.004$ & & $0.078 \pm 0.007$ & & $p \leq 0.05$ & II.288+0.489 & & $|2.89| \pm 0.303$ & & $p \leq 0.05$ \\
\hline Cauncharina & $0.012 \pm 0.001$ & 74 & $0.021+0.002$ & 73 & $p \leq 0.05$ & $6.684 \pm 1.138$ & 41 & $6.368+1.562$ & 51 & $p=0.5 \mathrm{I}$ \\
\hline
\end{tabular}

Maíz seco blanco

Mazamorra

\begin{tabular}{lllllllllll} 
Maíz entero & $0.046 \pm 0.001$ & & $0.077 \pm 0.001$ & & $p \leq 0.05$ & $9.449 \pm 1.233$ & & $10.563 \pm 0.598$ & $p=0.29$ \\
\hline Maíz trillado & $0.048 \pm 0.001$ & -5 & $0.065 \pm 0.004$ & 16 & $p \leq 0.05$ & $6.478 \pm 0.373$ & 31 & $7.531 \pm 0.493$ & 29 & $p \leq 0.05$ \\
\hline Mazamorra & $0.01 I \pm 0.002$ & 75 & $0.012 \pm 0.001$ & 84 & $p=0.50$ & $3.763 \pm 0.450$ & 60 & $5.272 \pm 0.975$ & 50 & $p \leq 0.05$
\end{tabular}

Envuelto añejo

\begin{tabular}{|c|c|c|c|c|c|c|c|c|c|c|}
\hline Maíz entero & $0.046 \pm 0.001$ & & $0.077 \pm 0.001$ & & $p \leq 0.05$ & $9.449 \pm 1.233$ & & $10.563 \pm 0.598$ & & $p=0.29$ \\
\hline Maíz trillado & $0.048+0.001$ & -5 & $0.065 \pm 0.004$ & 16 & $p \leq 0.05$ & $6.478+0.373$ & 31 & $7.531 \pm 0.493$ & 29 & $p \leq 0.05$ \\
\hline Masa & $0.021 \pm 0.002$ & 56 & $0.028+0.001$ & 56 & $p \leq 0.05$ & $4.204 \pm 0.313$ & 56 & $5.008+1.149$ & 53 & $p=0.28$ \\
\hline Envuelto añejo & $0.014 \pm 0.001$ & 70 & $0.024 \pm 0.001$ & 69 & $p \leq 0.05$ & $4.498 \pm 1.129$ & 52 & $4.333 \pm 0.866$ & 59 & $p=0.83$ \\
\hline
\end{tabular}

Arepa

\begin{tabular}{|c|c|c|c|c|c|c|c|c|c|c|}
\hline Maíz entero & $0.046 \pm 0.001$ & & $0.077 \pm 0.001$ & & $p \leq 0.05$ & $9.449 \pm 1.233$ & & $10.563 \pm 0.598$ & & $p=0.29$ \\
\hline Maíz trillado & $0.048+0.001$ & -5 & $0.065+0.004$ & 16 & $p \leq 0.05$ & $6.478+0.373$ & 31 & $7.53 I \pm 0.493$ & 29 & $p \leq 0.05$ \\
\hline Maíz cocinado & $0.035 \pm 0.001$ & 23 & $0.035 \pm 0.005$ & 55 & $p=0.82$ & $4.927 \pm 0.070$ & 48 & $4.228 \pm 0.403$ & 60 & $p \leq 0.05$ \\
\hline Masa sin margarina y sal & $0.036 \pm 0.001$ & 22 & $0.036 \pm 0.002$ & 47 & $p=0.81$ & $5.258+0.510$ & 44 & $5.161 \pm 1.829$ & 51 & $p=0.51$ \\
\hline Masa con margarina y sal & $0.031 \pm 0.001$ & 33 & $0.036+0.001$ & 47 & $p \leq 0.05$ & $4.424 \pm 0.606$ & 53 & $4.527 \pm 0.872$ & 57 & $p=0.83$ \\
\hline Arepa & $0.027 \pm 0.001$ & 41 & $0.027 \pm 0.001$ & 35 & $p=0.81$ & $4.199+0.289$ & 56 & $6.365 \pm 1.848$ & 40 & $p=0.13$ \\
\hline
\end{tabular}

(Continúa) 
(Continuación)

Maíz tierno Amarillo

Choclo cocido

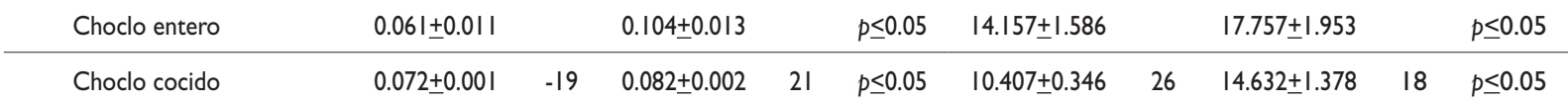

Choclo frito

\begin{tabular}{|c|c|c|c|c|c|c|c|c|c|c|}
\hline Choclo entero & $0.061 \pm 0.011$ & & $0.104 \pm 0.013$ & & $p \leq 0.05$ & $14.157 \pm 1.586$ & & $17.757 \pm 1.953$ & & $p \leq 0.05$ \\
\hline Choclo frito & $0.056+0.002$ & 8 & $0.107 \pm 0.005$ & -3 & $p \leq 0.05$ & $9.924 \pm 2.480$ & 30 & $15.264+1.390$ & 14 & $p \leq 0.05$ \\
\hline
\end{tabular}

Envuelto choclo

\begin{tabular}{|c|c|c|c|c|c|c|c|c|c|c|}
\hline Choclo entero & $0.061 \pm 0.011$ & & $0.104 \pm 0.013$ & & $p \leq 0.05$ & $14.157 \pm 1.586$ & & $17.757 \pm 1.953$ & & $p \leq 0.05$ \\
\hline Masa & $0.037 \pm 0.001$ & 38 & $0.107 \pm 0.001$ & -3 & $p \leq 0.05$ & $16.412 \pm 2.118$ & -16 & $33.338 \pm 0.415$ & -88 & $p \leq 0.05$ \\
\hline Envuelto choclo & $0.050+0.020$ & 17 & $0.102+0.014$ & 2 & $p<0.05$ & $9.820+1.635$ & 31 & $\mid 5.444+1.448$ & 13 & $p<0.05$ \\
\hline
\end{tabular}

Arepa de choclo

\begin{tabular}{lllllllllll} 
Choclo entero & $0.061 \pm 0.011$ & & $0.104 \pm 0.013$ & & $p \leq 0.05$ & $14.157 \pm 1.586$ & & $17.757 \pm 1.953$ & $p \leq 0.05$ \\
\hline Masa & $0.037 \pm 0.001$ & 38 & $0.107 \pm 0.001$ & -3 & $p \leq 0.05$ & $16.412 \pm 2.118$ & -16 & $33.338 \pm 0.415$ & -88 & $p \leq 0.05$ \\
Arepa de choclo & $0.049 \pm 0.032$ & 20 & $0.074 \pm 0.002$ & 29 & $p=0.51$ & $10.323 \pm 0.316$ & 27 & $16.755 \pm 1.380$ & 6 & $p \leq 0.05$
\end{tabular}

Maíz Tierno Blanco

Choclo cocido

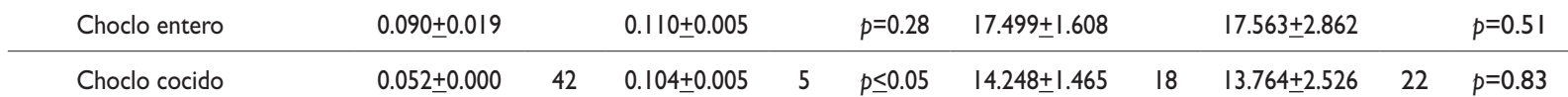

Choclo frito

\begin{tabular}{|c|c|c|c|c|c|c|c|c|c|c|}
\hline Choclo entero & $0.090 \pm 0.019$ & & $0.110 \pm 0.005$ & & $p=0.28$ & $17.499+1.608$ & & $17.563 \pm 2.862$ & & $p=0.51$ \\
\hline Choclo frito & $0.016 \pm 0.002$ & 83 & $0.091 \pm 0.007$ & 18 & $p \leq 0.05$ & $11.690 \pm 0.320$ & 33 & $11.158 \pm 1.767$ & 36 & $p=0.51$ \\
\hline \multicolumn{11}{|l|}{ Envuelto choclo } \\
\hline Choclo entero & $0.090 \pm 0.019$ & & $0.110+0.005$ & & $p=0.28$ & $17.499+1.608$ & & $17.563+2.862$ & & $p=0.51$ \\
\hline Masa & $0.05 I \pm 0.004$ & 44 & $0.081 \pm 0.003$ & 26 & $p \leq 0.05$ & $13.610 \pm 0.976$ & 22 & $16.270 \pm 1.505$ & 7 & $p \leq 0.05$ \\
\hline Envuelto choclo & $0.06 \pm 0.007$ & 34 & $0.097 \pm 0.011$ & 12 & $p \leq 0.05$ & $11.898+2.059$ & 32 & $15.620 \pm 3.470$ & II & $p=0.13$ \\
\hline \multicolumn{11}{|l|}{ Arepa de choclo } \\
\hline Choclo entero & $0.090 \pm 0.019$ & & $0.110+0.005$ & & $p=0.28$ & $17.499+1.608$ & & $17.563+2.862$ & & $p=0.5 \mathrm{I}$ \\
\hline Masa & $0.05 I \pm 0.004$ & 44 & $0.08 I \pm 0.003$ & 26 & $p \leq 0.05$ & $13.610 \pm 0.976$ & 22 & $16.270 \pm 1.505$ & 7 & $p \leq 0.05$ \\
\hline Arepa choclo & $0.052 \pm 0.002$ & 42 & $0.095+0.004$ & 14 & $p \leq 0.05$ & $14.783+1.217$ & 15 & $16.839 \pm 1.222$ & 4 & $p=0.13$ \\
\hline
\end{tabular}

* Pérdida

‡ Quality protein maize

$\S$ Valor p, comparación entre común y QPM

\# $g$ de triptófano/ $100 \mathrm{~g}$ de muestra seca

$\& \%$ de pérdida

${ }^{*} \mathrm{~g}$ de proteína soluble/kg de muestra seca

$\mathrm{ND}=$ no detectado 


\section{Cuadro III}

TRIPTÓFANO (PROMEDIO \pm DE) EN EL GRANO ENTERO, PASOS INTERMEDIOS Y RECETAS ELABORADAS CON MAíZ COMÚN y maíz Qpm, (n=3). Centro Internacional de Agricultura Tropical, 2008-2009

\begin{tabular}{ccc} 
Común & & $\begin{array}{c}Q P M^{*} \\
\mathrm{mg} / \mathrm{gN}\end{array}$ \\
$\begin{array}{c}\mathrm{mg} / \mathrm{gN} \\
\text { Maíz seco amarillo } \\
\text { Mazamorra } \\
\text { Maíz en grano }\end{array}$ & $38.998 \pm 2.180$ & $62.746 \pm 7.164$ \\
\hline Maíz trillado & $17.412 \pm 1.750$ & $44.227 \pm 8.231$ \\
\hline Mazamorra & & $11.726 \pm 1.224$ \\
Envuelto pelado & $38.998 \pm 2.180$ & $62.746 \pm 7.164$ \\
\hline Maíz en grano & $9.495 \pm 0.940$ & $14.793 \pm 0.574$ \\
\hline Maíz pelado & $10.246 \pm 1.310$ & $21.641 \pm 0.713$ \\
\hline Maíz remojado & $10.892 \pm 0.191$ & $33.336 \pm 1.495$ \\
\hline Masa & $10.359 \pm 0.349$ & $24.637 \pm 0.433$ \\
\hline Envuelto pelado & & \\
Cauncharina & $38.998 \pm 2.180$ & $62.746 \pm 7.164$ \\
\hline Maíz en grano & $15.440 \pm 1.509$ & $24.671 \pm 2.540$ \\
\hline Cauncharina & &
\end{tabular}

Maíz seco blanco

\begin{tabular}{lcc}
$\begin{array}{l}\text { Mazamorra } \\
\text { Maíz en grano }\end{array}$ & $28.915 \pm 0.657$ & $58.752 \pm 1.042$ \\
\hline Maíz trillado & $33.842 \pm 0.521$ & $55.916 \pm 3.606$ \\
\hline $\begin{array}{l}\text { Mazamorra } \\
\text { Envuelto añejo } \\
\text { Maíz en grano }\end{array}$ & $7.880 \pm 1.861$ & $11.022 \pm 0.926$ \\
\hline Maíz trillado & $28.915 \pm 0.657$ & $58.752 \pm 1.042$ \\
\hline Masa & $33.842 \pm 0.521$ & $55.916 \pm 3.606$ \\
\hline Envuelto añejo & $15.710 \pm 1.366$ & $29.982 \pm 0.188$ \\
\hline $\begin{array}{c}\text { Arepa } \\
\text { Maíz en grano }\end{array}$ & $10.271 \pm 0.560$ & $25.574 \pm 0.460$ \\
\hline Maíz trillado & $28.915 \pm 0.657$ & $58.752 \pm 1.042$ \\
\hline Maíz cocinado & $33.842 \pm 0.521$ & $55.916 \pm 3.606$ \\
\hline Masa sin margarina y sal & $21.398 \pm 0.512$ & $29.430 \pm 4.090$ \\
\hline Masa con margarina y sal & $20.866 \pm 0.894$ & $33.956 \pm 0.535$ \\
\hline Arepa & $18.577 \pm 1.338$ & $25.610 \pm 0.287$ \\
\hline
\end{tabular}

Maíz tierno blanco

Choclo cocido

\begin{tabular}{lll} 
Choclo & $41.535 \pm 7.259$ & $43.109 \pm 6.520$ \\
\hline Choclo cocido & $45.805 \pm 1.890$ & $56.795 \pm 1.734$
\end{tabular}

Choclo frito

\begin{tabular}{lcr} 
Choclo & $41.535 \pm 7.259$ & $43.109 \pm 6.520$ \\
\hline Choclo frito & $7.841 \pm 0.668$ & $41.319 \pm 1.740$
\end{tabular}

Envuelto choclo

\begin{tabular}{lll} 
Choclo & $41.535 \pm 7.259$ & $43.109 \pm 6.520$ \\
\hline Masa & $26.187 \pm 1.891$ & $43.804 \pm 1.545$ \\
\hline Envuelto choclo & $30.931 \pm 2.980$ & $48.828+4.542$
\end{tabular}

Arepa de choclo

\begin{tabular}{lll} 
Choclo & $41.535 \pm 7.259$ & $43.109+6.520$ \\
\hline Masa & $26.187 \pm 1.891$ & $43.804 \pm 1.545$ \\
\hline Arepa de choclo & $26.591 \pm 1.320$ & $54.422+2.073$
\end{tabular}

\footnotetext{
* Quality Protein Maize
} 


\section{Cuadro IV \\ DigestibiLIDAD IN VITRO DE PROTEÍNA (PROMEDIO \pm DE) \\ EN RECETAS ELABORADAS CON MAíZ COMÚN Y MAíZ Qpm (n=3). Centro Internacional de Agricultura TROPICAL, 2008-2009}

\begin{tabular}{lccc} 
& $\begin{array}{c}\text { Común } \\
\%\end{array}$ & $\begin{array}{c}Q P M^{*} \\
\%\end{array}$ & Valor $P^{\ddagger}$ \\
Maíz seco amarillo & & & \\
Mazamorra & $84.562 \pm 0.499$ & $81.914 \pm 0.220$ & $p \leq .05$ \\
\hline Envuelto pelado & $85.540 \pm 1.792$ & $84.158 \pm 0.072$ & $p=0.51$ \\
\hline Cauncharina & $75.187 \pm 1.733$ & $77.703 \pm 2.067$ & $p=0.13$
\end{tabular}

\begin{tabular}{llll}
$\begin{array}{l}\text { Maíz seco blanco } \\
\text { Mazamorra }\end{array}$ & $80.430 \pm 0.410$ & $83.374 \pm 3.125$ & $p \leq 0.05$ \\
\hline Envuelto añejo & $82.336 \pm 0.322$ & $82.300 \pm 0.052$ & $p=0.51$ \\
\hline Arepa & $81.123 \pm 1.694$ & $80.369 \pm 0.792$ & $p=0.83$
\end{tabular}

Maíz tierno amarillo

\begin{tabular}{llll} 
Choclo cocido & $83.283 \pm 3.089$ & $78.970 \pm 1.105$ & $p=0.13$ \\
\hline Choclo frito & $81.799 \pm 1.080$ & $80.152 \pm 1.404$ & $p=0.28$ \\
\hline Envuelto choclo & $79.114 \pm 0.884$ & $78.330 \pm 0.273$ & $p=0.13$ \\
\hline Arepa choclo & $76.984 \pm 0.954$ & $77.491 \pm 0.407$ & $p=0.51$
\end{tabular}

Maíz tierno blanco

\begin{tabular}{llll} 
Choclo cocido & $77.570 \pm 0.496$ & $79.229 \pm 0.826$ & $p \leq 0.05$ \\
\hline Choclo frito & $78.065 \pm 1.065$ & $78.668 \pm 0.916$ & $p=0.51$ \\
\hline Envuelto choclo & $77.968 \pm 0.219$ & $79.078 \pm 0.082$ & $p \leq 0.05$ \\
\hline Arepa choclo & $77.057 \pm 0.324$ & $75.693 \pm 1.107$ & $p=0.13$
\end{tabular}

* Quality protein maize

‡Valor $p$ según análisis estadístico

Se ha dicho que las proteínas del maíz se ven afectadas con la maduración, lo que disminuye las glutelinas y proteínas solubles en soluciones ácidas y alcalinas. De esta manera, disminuyen la lisina, la metionina y el triptófano. ${ }^{1}$ Esta situación se observa en este estudio, ya que la concentración de triptófano del maíz QPM empleado es mayor en el grano tierno que en el grano seco, tanto para maíz amarillo como blanco.

La Organización Mundial de la Salud (2007) recomienda el consumo de $46.25 \mathrm{mg}$ de triptófano/g N para niños de 1 a 2 años. ${ }^{29}$ Todos los granos QPM cumplen con esta recomendación con la excepción de maíz tierno blanco. Ningún grano de maíz común tiene la concentración recomendada de triptófano. Los procesos que mejor preservaron los niveles recomendados de triptófano fueron cauncharina en el MSA, arepa en el MSB, arepa de choclo en el MTA y choclo cocido en el MTB.

Proteína soluble, maíz seco: El MSA entero QPM presentó mayor concentración de PS. Mientras que el MSB entero no presentó diferencia entre QPM y MC. Diversos autores reportan tendencias similares para proteína cruda (PC) (nitrógeno x 6.25) a las observadas en este estudio. ${ }^{10,11,19,20,23-25,28}$ No obstante, ellos no hacen diferencia en el color del maíz, como sí ocurre en este estudio.

En los pasos intermedios a excepción del MSA trillado, masa para envuelto pelado (EVP), masa para arepa con y sin sal y con margarina, se presentó mayor PS en los QPM. Tras la cocción se presentó tendencia de pérdida de PS en todas las recetas, al igual que reportó Chávez ${ }^{10}$ para $\% \mathrm{~N}$ en opaco-2. Sin embargo, otros autores no reportan tendencias de pérdida. ${ }^{25,28,30}$

Así como se reporta en otros estudios, ${ }^{10,27}$ el proceso de trilla presenta pérdidas de proteína. En este estudio la mayor pérdida de PS se observó en este proceso, posiblemente por la remoción del pericarpio y el germen, ya que en este último se encuentran gran parte de las proteínas del maíz. ${ }^{1,24}$ La cauncharina también presentó pérdidas, sin llevar a cabo este proceso. Esto hace suponer que el tratamiento térmico afecta la PS, posiblemente por cambio en la estructura de las proteínas que las hace insolubles en el medio empleado (alcalino) para la extracción.

La mazamorra de MSA de MC y el EVP y mazamorra de MSB QPM presentaron mayor concentración de PS; en las demás no hubo diferencia como igualmente reportó Graham et al. ${ }^{27}$ Sin embargo, otros autores reportaron mayor $\% \mathrm{~N}$ o $\mathrm{PC}$ en recetas de QPM u opaco-2. ${ }^{10,11,28}$

La pérdida de PS para ambos maíces estuvo entre 5 y $79 \%$, sin presentarse tendencia marcada para uno de los dos. Las recetas con mayor y menor pérdida fueron envuelto pelado (79\%) y mazamorra de MSA (5\%) para MC, y envuelto pelado (74\%) y arepa (40\%) para QPM. Como se observa, el envuelto pelado presenta mayor pérdida para uno y otro.

Proteína soluble, maíz tierno: Se observó que con la cocción se presentan pérdidas de PS entre 15 y $33 \%$ para MC, y 4 y $36 \%$ para QPM.

Digestibilidad in vitro de proteína, maíz seco: En la mazamorra de MSA de MC y mazamorra de MSB QPM se encontró mayor DP, con valores de 85 y $83 \%$, respectivamente, mayores a los de Fufa et al., ${ }^{20}$ quien reportó valores para maíz hervido entre 77 y $80 \%$ para MC, y $78 \%$ para QPM. Las demás recetas no presentaron diferencia, similar a lo reportado por otros investigadores..$^{20,22}$ 
Ortega et al. ${ }^{11}$ reportaron mayor DP en la tortilla elaborada con MC que con QPM, tras el proceso de nixtamalización. En este estudio para el EVP que lleva un proceso similar, no se encontró diferencia entre QPM y MC, debido, posiblemente, a que ellos emplearon maíz blanco y a que los procesos que acompañan la elaboración del EVP son diferentes al proceso de elaboración de tortilla.

Digestibilidad invitro de proteína maíz tierno: Se encontró mayor DP en las recetas choclo cocido (79\%) y envuelto de choclo (79\%) de MTB de QPM, mientras que en las otras de MTB y en las de MTA no se encontró diferencia entre QPM y MC.

Los valores de DP para maíz seco y tierno, estuvieron entre 75\% (cauncharina) y 86\% (EVP) para MC, y 76\% (arepa choclo de MTB) y 84\% (EVP) para QPM. El EVP es la receta que presenta mayor DP para ambos maíces; y aunque no presenta diferencia entre QPM y $\mathrm{MC}$, su DP se encuentra por encima de las recetas que sí presentan diferencia.

\section{Conclusiones}

En general, las recetas elaboradas con maíz QPM presentaron mejor calidad proteica que las elaboradas con maíz común ya que la mayoría presentó igual digestibilidad que las preparadas con maíz común, pero mayor concentración de triptófano y proteína soluble. De las 10 recetas elaboradas, el contenido de triptófano fue mayor en 9 QPM y la proteína soluble en 6. Se encontró sólo un caso donde la receta de maíz común tuvo mayor proteína soluble que la de maíz QPM. Es de gran importancia resaltar que en la mayoría de los casos, los procesos de cocción afectaron la calidad proteica al disminuir la concentración de triptófano y proteína soluble, tanto en el maíz QPM como en el maíz común.

\section{Agradecimientos}

Financiamiento: Monsanto Fund, Agencia Canadiense de Desarrollo Internacional (CIDA7034161), a través del Proyecto AgroSalud y el Centro Internacional de Agricultura Tropical, CIAT. Se agradece al CIMMYT y al ICA por las muestras de maíz. A los Laboratorios de Calidad Nutricional y Servicios Analíticos, a CLAYUCA, y a los Programas de Mejoramiento de Arroz y Yuca por sus instalaciones. A Marlene Rosero por la revisión editorial. A la Universidad del Cauca, docente Ana de Dios Elizalde, la comunidad caucana y a los profesionales Freddy Salazar, Sandra Salazar, Sayda Pico, Andrés Escobar e Ingrid Aragón por su constante apoyo y colaboración.

\section{Referencias}

I. Organización de las Naciones Unidas para la Agricultura y la Alimentación, FAO. El maíz en la nutrición humana. [monografía en internet]. Roma: FAO, 1993. [consultado 2009 Mayo I5]. Disponible en: http://www.fao.org/docrep/t0395s/t0395s00.htm

2. Instituto Colombiano de Bienestar Familiar, ICBF. Encuesta nacional de la situación nutricional en Colombia, 2005. Bogotá: ICBF, 2006.

3. Faostat.fao.org. [sitio de internet]. (C) FAO Dirección de Estadística 2009. [actualizado 2009 febrero; consultado 2009 mayo I8]. Disponible en: http://faostat.fao.org

4. Institute of Medicine of the National Academies. Dietary reference intakes for energy, carbohydrate, fiber, fat, fatty acids, cholesterol, protein and amino acids. Washington, D.C.:The National Academies Press, 2005. 5. Nestel P, Bouis H, Meenakshi J.V., Pfeiffer W. Biofortification of staple food crops. J Nutr. 2006; 136:1064-7.

6. Panel On Quality Protein Maize. Quality-Protein Maize.Washington, D.C.: National Academy Press, 1988.

7. Morales M. Efecto del consumo de maíz de alta calidad proteínica en niño(a)s de familias indígenas de las regiones Mazateca y Mixe del estado de Oaxaca: una estrategia agronómica de desarrollo entre campesinos que practican agricultura de subsistencia (tesis). México: Colegio de Postgraduados. Instituto de Enseñanza e Investigación en Ciencias Agrícolas. 2002.

8. Ortega E, Coulson A, Ordóñez L. Pachón H. Efectos de la ingesta de maíz de alta calidad de proteína (QPM) versus maíz convencional en el crecimiento y la morbilidad de niños nicaragüenses desnutridos de I a 5 años de edad.Arch Latinoam Nutr. 2008;58(4).377-85.

9. Gunaratna NS, De Groote H, Nestel P, Pixley KV, McCabe GP.A metaanalysis of community based studies on quality protein maize. Food Policy. 2010;35(3):202-210.

10. Chávez JF. Composición del maíz opaco-2 venezolano.Análisis y calidad biológica de la arepa de opaco-2 y de maíz corriente.Arch Latinoam Nutr. 1972;2(I): 147-60.

II. Ortega E,Villegas E,Vasal S.A comparative study of protein changes in normal and quality protein maize during tortilla making. Cereal Chem. 1986;63(5):446-5।.

I2. Muñoz López MdM, Revelo MC, Pachón H. El consumo y la producción familiar de fríjol, maíz, yuca, batata y arroz en un municipio rural en Colombia: Evaluación de la posibilidad de implementar la biofortificación de cultivos. Persp Nutr Humana. 2008; I0(I): I I-2I. 13. Villegas A,Vasal S, Bjarnason M. Quality protein maize: What is it and how was it developed. 1992. In Mertz ET (Ed). Quality protein maize. American association of cereal chemists, St. Paul, Minnesota. P. 27-48. 14. Nurit E, Tiessen A, Pixley KV, Palacios-Rojas N. Reliable and inexpensive colorimetric method for determining protein-bound tryptophan in maize kernels. J Agric Food Chem. 2009;57:7233-8. I5. Vivek BS, Krivanek AF, Palacios-Rojas N, Twumasi-Afriyie S, Diallo AO. Breeding Quality Protein Maize (QPM): Protocols for developing QPM cultivars. Mexico, D.F.: CIMMYT, 2008.

16. Lowry O, Rosenbrough N, Farr L, Randall R. Protein measurement with the folin phenol reagent. J Biol Chem. 195I;193(I):265-75. 17. Hsu HW,Vavak, DL, Satterlee LD, Miller GA.A multienzyme technique for estimating protein digestibility. J Food Sci. 1977;42(3): 1269-73. I8. McDonough F, Sarwar G, Steinke F, Slump P, García S, Boisen S. In vitro assay for protein digestibility: Interlaboratory study. J Assoc Off Anal Chem. 1990; 73(4):622-5.

19. Del-Angel A, Sotelo A. Nutritive value of mixtures using chick-peas with wheat, triticale, normal and opaque-2 corns. J. Nutr. 1982; I 2: |474-80. 20. Fufa H,Akalu G,Wondimu A, Taffesse S, Gebre T, Schlosser K, et al. Assessment of protein nutritional quality and effects of traditional 
processes:A comparison between Ethiopian quality protein maize and five Ethiopian adapted normal maize cultivars. Nahrung/food. 2003;47(4):269-73. 21.Vázquez M, Morales M, Rendón E. Tortillas elaboradas con maíz de alta calidad proteínica. Edo de México: INIFAP, 2004.

22. Pachón H, Ortiz DA,Araujo C, Blair MW, Restrepo J. Iron, zinc and protein bioavailability proxy measures of meals prepared with nutritionally enhanced beans and maize.J Food Sci. 2009;74 (5):HI47-54.

23. Serna-Saldivar S, Amaya C, Herrera P, Melesio J, Preciado R, Terron $A$, et al. Evaluation of the lime-cooking and tortilla making properties of quality protein maize hybrids grown in Mexico. Plant Foods Hum Nutr. 2008;63:119-25.

24. Mendoza-Elos M,Andrio-Enríquez E, Juarez-Goiz JM, MosquedaVillagómez C, Lataurnerie-Moreno L, Castañón-Nájera G, et al. Contenido de lisina y triptofano en genotipos de maíz de alta calidad proteica y normal. Universidad y Ciencia. 2006;22(2):153-6I.

25. Sullivan JS, Knabe DA, Bockholt AJ, Gregg EJ. Using ultrasound technology to predict nutritional value of quality protein maize and food corn for starter and growth pigs. J Anim Sci. 1989;67:1285-92.
26. Amaya-Guerra C,Alanis-Guzmán MG, Serna-Saldivar S. Effects of soybean fortification on protein quality of tortilla-based diets produced from regular and quality protein maize. Plant Foods Hum Nutr. 2004:59:45-50.

27. Graham G, Glover D, Lopez G, Morales E, MacLean W. Nutritional value of normal, opaque-2 and sugary-2 opaque-2 maize hybrids for infants and children. I. Digestibility and utilization.J Nutr. 1980; I 10:106 I-9.

28. Bressani R, Elias LG, Gómez-Brenes RA. Protein quality of opaque-2 corn: evaluation in rats.J Nutr. 1968;97:173-80.

29. World Health Organization. Protein and amino acid requirements in human nutrition: Report of a Joint WHO/FAO/UNU expert consultation. Geneva,WHO, 2007.

30. Serna-Saldivar SO, Knabe DA, Rooney LW,Tanksley TD. Effects of lime cooking on energy and protein digestibilities of maize and sorghum. Cereal Chem. 1987;64(4):247-52. 